\title{
ANALISIS BEBAN KERJA MENGGUNAKAN METODE NASA-TLX PADA CV. BAHAGIA JAYA ALSINDO
}

\author{
Anita Pramesti ${ }^{1}$, Endang Suhendar ${ }^{2}$ \\ Teknik Industri, Universitas Indraprasta PGRI \\ anitapramesti2@gmail.com ${ }^{1}$, endangsuhendar@ac.id ${ }^{2}$
}

Submitted June 29, 2020; Revised December 23, 2020; Accepted December 29, 2020

\begin{abstract}
Abstrak
CV Bahagia Jaya Alsindo merupakan bagian dari PT. Bahagia Jaya Sejahtera yang tergabung dalam Bahagia Jaya Group yang di kenal sebagai produsen alat/mesin Pertanian, Perindustrian, Perkebunan, Peternakan dan perikanan. Permasalahan yang timbul akibat banyaknya tuntutan kerja dari perusahaan ke operator produksi yang mengakibatkan proses produksi tidak berjalan maksimal, adanya indikasi turnover karyawan dan ruangan kerja yang tidak nyaman sehingga membuat karyawan merasa stress saat kerja. Penelitian ini bertujuan untuk mengetahui beban kerja terhadap operator produksi mesin hammer mill bagian pengukuran dan pemotongan bahan, assembling, pengecatan, dan finishing good, untuk mengetahui faktor-faktor penyebab adanya beban kerja mental dengan indikasi turnover karyawan dan untuk mengurangi beban kerja mental yang di rasakan oleh operator produksi hammer mill. Metode yang digunakan dalam penelitian ini adalah NASA-TLX (Task Load Index) dengan dua tahap yaitu tahap pembobotan dan tahap pemberian nilai. Hasil penelitian awal di peroleh nilai WWL (Weight Workload) operator bagian pengukuran dan pemotongan bahan sebesar 73,56, bagian Assembling sebesar 76,00, bagian pengecatan sebesar 72,00, dan finishing good sebesar 73,33 dimana hasil tersebut mengalami beban kerja mental tinggi. Usulan perbaikan dilakukan dengan mengadakan psikotest, memberikan training, menyediakan Alat Pelindung Diri (APD) saat bekerja dan mengadakan pergantian shift kerja.
\end{abstract}

Kata Kunci: Beban Kerja, Beban Kerja Mental, NASA-TLX

\begin{abstract}
CV Bahagia Jaya Alsindo is part of PT. Bahagia Jaya Sejahtera, a member of the Bahagia Jaya Group, is known as a producer of agricultural, industrial, agricultural, livestock and fishery equipment / machinery. Problems arising from the many demands of work from the company to the production operator that resulted in the production process not running optimally, there are indications of employee turnover and work space that is not comfortable so that makes employees feel stressed at work. This study aims to determine the workload of hammer mill machine production operators measuring and cutting materials, assembling, painting, and finishing good, to determine the factors that cause mental workload with employee turnover indications and to reduce the mental workload felt by hammer mill production operators. The method used in this study is NASA-TLX (Task Load Index) with two stages, namely the weighting stage and the grading stage. Initial research results obtained WWL (Weight Workload) operator part of the measurement and cutting materials by 73.56, the Assembling section by 76.00, the painting part by 72.00, and finishing good by 73.33 where the results experienced a mental workload high. Proposed improvement is done by holding psych tests, providing training, providing Personal Protective Equipment (PPE) while working and holding work shifts.
\end{abstract}

Key Words : Workload, Mental Workload, NASA-TLX

\section{PENDAHULUAN}

CV. Bahagia Jaya Alsindo bergerak dalam produksi mesin dan alat Pertanian,
Perkebunan, Peternakan, Pra dan Pasca Panen. Salah satu produk yang dihasilkan adalah mesin Hammer Mill yang berfungsi 
untuk memperkecil ukuran bahan baku produksi seperti gandum hingga menjadi tepung yang lebih halus. Dalam proses produksi mesin Hammer Mill ada beberapa tahapan proses produksi, diantaranya adalah proses pengukuran dan pemotongan bahan, assembling, pengecatan hingga proses finishing good.

Ergonomi adalah ilmu, seni dan penerapan teknologi untuk menyerasikan atau menyeimbangkan antara segala fasilitas yang digunakan baik dalam beraktivitas maupun istirahat dengan kemampuan dan keterbatasan manusia baik fisik maupun mental sehingga kualitas hidup secara keseluruhan menjadi lebih baik[1]. Ergonomi juga digunakan oleh berbagai macam ahli/profesional pada bidangnya, misalnya ahli anatomi, arsitektur, perancangan produk industri, fisika, fisioterapi, terapi pekerjaan, psikologi dan teknik industri[2]. Beban kerja adalah suatu istilah yang digunakan untuk menyebut harga atau cost dari pencapaian suatu target kegiatan[3]. Beban kerja adalah istilah yang mencangkup dimensi yang sangat luas tentang aktivitas manusia, tetapi istilah beban kerja mental dibatasi pada aktivitas mental yang utama saja, dimana koordinasi aktivitas fisik seperti kelelahan otot tidak di perhitungkan sbagai faktor yang penting. Namun konsep tentang beban kerja mental itu sendiri masih sulit didefinisikan secara tepat karena sifatnya yang multidimensi dan multidisiplin[4].

Tuntutan tugas (beban tugas) adalah tujuan yang ingin dicapai atau waktu yang diizinkan untuk melakukan tugas, dan tingkat kinerja yang tugasnya harus diselesaikan. Faktor-faktor yang mempengaruhi informasi dan peralatan menyediakan lingkungan tugas, keterampilan subjek dan pengalaman, strategi yang diadopsi, dan respons emosional terhadap situasi[5].
Permendagri No. 12/2008 menyatakan bahwa beban kerja adalah besaran pekerjaan yang harus dipikul oleh suatu jabatan/unit organisasi dan merupakan hasil kali antara volume kerja dan norma waktu. Jika kemampuan pekerja lebih tinggi daripada tuntutan pekerjaan, akan muncul perasaan bosan. Namun sebaliknya, jika kemampuan pekerja lebih rendah daripada tuntutan pekerjaan, maka akan muncul kelelahan yang lebih[6]. Beban kerja psikologis dapat berupa tekanan karena diharuskan dalam mencapai prestasi kerja yang berlebihan dan lainnya. Kemampuan kerja seseorang tenaga kerja akan berbeda satu sama lain[7].

Permasalahan dalam proses produksi yang sering terjadi melibatkan banyaknya penurunan kualitas operator di lantai produksi, terjadinya turn over operator sehingga menyebabkan pekerjaan yang kurang efektif, dan ruangan kerja yang tidak memadai sehingga menimbulkan rasa tidak nyaman pada operator saat bekerja.

Tujuan dalam penelitian ini untuk mengetahui faktor-faktor penyebab adanya beban kerja mental sehingga dapat mengurangi beban kerja yang di rasakan oleh operator produksi.

NASA-TLX (National Aeronautics and Space Administration Task Load Index) dikembangkan oleh Sandra G. Hart dari NASA-Ames Research Center dan Lowell E. Staveland dari San Jose State University pada tahun 1981. Metode dalam NasaTLX berdasarkan kemunculannya di kembangkan sebanyak 9 faktor, tetapi di sederhanakan sehingga mempunyai 6 faktor yaitu [8]:

a. Mental Demand

b. Phsycal Demand

c. Temporal Demand

d. Own Performance

e. Effort

f. Frustation 
Penulis memilih metode tersebut karena metode NASA-TLX merupakan skala multi-dimensi yang dirancang untuk mendapatkan faktor penyebab beban kerja dari satu atau lebih operator di dalam ruangan produksi. Penulis juga menambahkan analisis Fishbone Diagram guna mengidentifikasi dan mengorganisasi sebab-akibat dari beban kerja operator di lantai produksi.

\section{METODE PENELITIAN}

Metode yang di pakai dalam penelitian ini adalah NASA-TLX dengan menggunakan alat bantu kuesioner. Metode NASA-TLX merupakan metode yang digunakan untuk menganalisis beban kerja mental yang dihadapi oleh pekerja yang harus melakukan berbagai aktivitas dalam pekerjaannya[9].

Metode penelitian dilakukan untuk mengetahui beban kerja pada operator produksi di bagian pengukuran dan pemotongan bahan, assembling, pengecatan, dan finishing good.

Data yang di perlukan untuk penelitian ini adalah data Paired Comparison dan Event Scoring. Setelah mengetahui hasil pengambilan data dari paired comparison dan event scoring, lalu melakukan perhitungan pemberian bobot (Weights) dan tahap pemberian peringkat (ratings).
a. Menghitung Paired
Comparison (Perbandingan Skala NASA-TLX)

Responden diminta untuk mengisi kuisioner dan menilai perbandingan antar skala yang paling dominan di rasakan responden ketika bekerja. Pengisian di lakukan dengan memberi tanda X (Silang) dalam kotak yang berwarna abu-abu untuk masingmasing deskripsi pekerjaan.
Tabel 1. Indikator Beban Mental (Paired Comparison)

\begin{tabular}{cc|c}
\hline No & \multicolumn{2}{c}{ Indikator Beban Mental } \\
\hline $\mathbf{1}$ & $\begin{array}{c}\text { Beban mental } \\
(\mathrm{MD})\end{array}$ & $\begin{array}{c}\text { Beban Temporal } \\
(\mathrm{TD})\end{array}$ \\
\hline $\mathbf{2}$ & $\begin{array}{c}\text { Beban } \\
\text { Temporal (TD) }\end{array}$ & $\begin{array}{c}\text { Performansi } \\
(\mathrm{OP})\end{array}$ \\
\hline $\mathbf{3}$ & $\begin{array}{c}\text { Beban mental } \\
(\mathrm{MD})\end{array}$ & $\begin{array}{c}\text { Tingkat Frustasi } \\
(\mathrm{FR})\end{array}$ \\
\hline $\mathbf{4}$ & Usaha (EF) & $\begin{array}{c}\text { Performansi } \\
(\mathrm{OP})\end{array}$ \\
\hline
\end{tabular}

\begin{tabular}{|c|c|c|}
\hline 5 & $\begin{array}{l}\text { Beban mental } \\
\text { (MD) }\end{array}$ & $\begin{array}{c}\text { Beban Fisik } \\
\text { (PD) }\end{array}$ \\
\hline 6 & $\begin{array}{l}\text { Beban Fisik } \\
\text { (PD) }\end{array}$ & $\begin{array}{l}\text { Tingkat Frustasi } \\
\text { (FR) }\end{array}$ \\
\hline 7 & $\begin{array}{c}\text { Beban } \\
\text { Temporal (TD) }\end{array}$ & Usaha (EF) \\
\hline 8 & $\begin{array}{l}\text { Beban mental } \\
\text { (MD) }\end{array}$ & $\begin{array}{l}\text { Performansi } \\
\text { (OP) }\end{array}$ \\
\hline 9 & $\begin{array}{c}\text { Beban } \\
\text { Temporal (TD) }\end{array}$ & $\begin{array}{l}\text { Tingkat Frustasi } \\
\text { (FR) }\end{array}$ \\
\hline 10 & $\begin{array}{l}\text { Beban Fisik } \\
\text { (PD) }\end{array}$ & $\begin{array}{c}\text { Beban } \\
\text { Temporal (TD) }\end{array}$ \\
\hline 11 & $\begin{array}{l}\text { Performansi } \\
\text { (OP) }\end{array}$ & $\begin{array}{l}\text { Tingkat Frustasi } \\
\text { (FR) }\end{array}$ \\
\hline 12 & $\begin{array}{l}\text { Beban Fisik } \\
\text { (PD) }\end{array}$ & Usaha (EF) \\
\hline 13 & Usaha (EF) & $\begin{array}{c}\text { Tingkat Frustasi } \\
\text { (FR) }\end{array}$ \\
\hline 14 & $\begin{array}{l}\text { Beban mental } \\
\text { (MD) }\end{array}$ & Usaha (EF) \\
\hline 15 & $\begin{array}{l}\text { Beban Fisik } \\
\text { (PD) }\end{array}$ & $\begin{array}{l}\text { Performansi } \\
\text { (OP) }\end{array}$ \\
\hline
\end{tabular}

b. Menghitung Event Scoring (Tahap Pemberian Nilai)

Event Scoring merupakan Tahap pemberian nilai terhadap beban kerja yang dialami oleh responden berkaitan dengan aktivitas yang dilakukannya. Para subjek diminta untuk mengisi form kuesioner dengan 6 pertanyaan yang masuk dalam 6 kategori skala metode NASA-TLX dengan nilai yang menurut para subjek sesuai dengan beban kerja yang mereka alami.

c. Menghitung Beban Kerja (Workload) dari masing-masing operator. Perhitungan beban kerja menggunakan rumus sebagai berikut : 


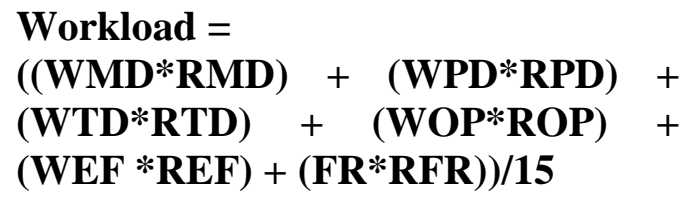

Keterangan:

$\mathbf{W}=$ Bobot beban kerja

$\mathbf{R}=$ Rating / Nilai

\section{HASIL DAN PEMBAHASAN}

Pada pengolahan data dalam menyelesaikan permasalahan pada $\mathrm{CV}$. Bahagia Jaya Alsindo untuk mengurangi beban kerja mental yang di rasakan oleh operator.

a. Perbandingan Skala (Paired Comparison)

Di bawah ini merupakan tabel hasil dari pengumpulan data Paired Comparison yang di lakukan operator produksi bagian pengukuran dan pemotongan bahan (example) $\mathrm{CV}$. Bahagia Jaya Alsindo. Angka dalam tabel diartikan sebagai seberapa besar beban kerja yang dirasakan responden pada indikator tersebut. Berikut hasil dari pemberian nilai :

Tabel 2. Paired Comparison, Proses Pengukuran dan Pemotongan Bahan

\begin{tabular}{|c|c|c|c|c|c|c|c|c|}
\hline \multirow{2}{*}{ No } & \multirow{2}{*}{ Nama } & \multicolumn{6}{|c|}{ Paired Comparison } & \multirow{2}{*}{ Total } \\
\hline & & PD & $\mathrm{MD}$ & $\mathrm{TD}$ & $\mathrm{PF}$ & $\mathrm{EF}$ & FR & \\
\hline 1 & Tasdik & 2 & 1 & 5 & 3 & 2 & 2 & 15 \\
\hline 2 & Darus & 1 & 2 & 3 & 2 & 3 & 4 & 15 \\
\hline 3 & Rian & 5 & 2 & 1 & 2 & 2 & 3 & 15 \\
\hline
\end{tabular}

b. Pemberian Nilai Terhadap Pekerjaan (Event Scoring)

Di bawah ini merupakan tabel hasil dari pengumpulan data Event Scoring yang di lakukan operator produksi bagian pengukuran dan pemotongan bahan (example) CV. Bahagia Jaya Alsindo. Angka dalam tabel diartikan sebagai seberapa besar beban kerja yang dirasakan responden pada indikator tersebut. Setelah responden mengisi lembar pemberian nilai, didapatkan hasil pengisian

kuisioner tersebut sebagai berikut :

Tabel 3. Event Scoring, Proses Pengukuran dan Pemotongan Bahan

\begin{tabular}{cccccccc}
\hline \multirow{2}{*}{ No } & \multirow{2}{*}{ Nama } & \multicolumn{5}{c}{ Event Scoring } \\
\cline { 3 - 8 } & & WPD & WMD & WTD & WPF & WEF & WFR \\
\hline $\mathbf{1}$ & Tasdik & 80 & 75 & 75 & 80 & 75 & 80 \\
\hline $\mathbf{2}$ & Darus & 70 & 80 & 75 & 70 & 70 & 70 \\
\hline $\mathbf{3}$ & Rian & 70 & 75 & 70 & 75 & 60 & 75 \\
\hline & & & & Sumber : Hasil Penelitian
\end{tabular}

c. Perhitungan Workload

Setelah kuisioner NASA - TLX diisi oleh responden melalui 2 tahap, yaitu tahap perbandingan skala (Paired Comparison) dan tahap pemberian nilai (Event Scoring) maka dapat diketahui nilai beban kerja dari masing-masing indikator pada karyawan Bagian pengukuran dan pemotongan Bahan, assembling, pengecatan, dan finishing good. Indikatornya meliputi beban mental/Mental Demand, beban fisik/Physical Demand, beban temporal/Temporal Demand, beban usaha/ Effort, beban performansi/Own Performance, dan beban frustasi/ Frustation level. Data hasil kuesioner tersebut kemudian dilakukan perhitungan untuk dicari nilai workloadnya dari tiap-tiap responden dengan menggunakan rumus sebagai berikut:

Workload Tasdik :

$$
\begin{aligned}
\frac{((2 x 80)+(1 \times 75)+}{(5 x 75)+(3 x 80)+(2 x 75)+(2 x 80))} & 15 \\
= & 77,33
\end{aligned}
$$

Langkah selanjutnya adalah menghitung jumlah total, mean, variansi dan standar deviasi dari hasil workload untuk semua responden (dapat di lihat pada tabel 4). 
1) Workload operator proses Pengukuran dan pemotongan bahan

Tabel 4. Workload, Proses Pengukuran dan pemotongan bahan

\begin{tabular}{|c|c|c|c|c|c|c|c|c|c|c|c|c|c|c|}
\hline \multirow[t]{2}{*}{ No } & \multirow[t]{2}{*}{ Nama } & \multicolumn{6}{|c|}{ Paired Comparison } & \multicolumn{6}{|c|}{ Event Scoring } & \multirow[t]{2}{*}{ Workload } \\
\hline & & PD & MD & TD & $\mathrm{PF}$ & $\mathrm{EF}$ & FR & WPD & WMD & WTD & WPF & WEF & WFR & \\
\hline 1 & Tasdik & 2 & 1 & 5 & 3 & 2 & 2 & 80 & 75 & 75 & 80 & 75 & 80 & 77,33 \\
\hline 2 & Darus & 1 & 2 & 3 & 2 & 3 & 4 & 70 & 80 & 75 & 70 & 70 & 70 & 72,33 \\
\hline 3 & Rian & 5 & 2 & 1 & 2 & 2 & 3 & 70 & 75 & 70 & 75 & 60 & 75 & 71,00 \\
\hline \multicolumn{8}{|c|}{ Jumlah } & 220 & 230 & 220 & 225 & 205 & 225 & 221 \\
\hline \multicolumn{8}{|c|}{ Mean } & 73,33 & 76,67 & 73,33 & 75,00 & 68,33 & 75,00 & 73,56 \\
\hline \multicolumn{8}{|c|}{ Variasi } & 33,33 & 8,33 & 8,33 & 25,00 & 58,33 & 25,00 & 11,15 \\
\hline \multicolumn{8}{|c|}{ Standar Deviasi } & 5,77 & 2,89 & 2,89 & 5,00 & 7,64 & 5,00 & 3,34 \\
\hline \multicolumn{8}{|c|}{ Maksimum } & 80,00 & 80,00 & 75,00 & 80,00 & 75,00 & 80,00 & 77,33 \\
\hline \multicolumn{8}{|c|}{ Minimum } & 70,00 & 75,00 & 70,00 & 70,00 & 60,00 & 70,00 & 71,00 \\
\hline
\end{tabular}

Tabel 5. Kategori Beban Kerja

\begin{tabular}{ccc}
\hline $\begin{array}{c}\text { Nilai } \\
(\text { Range })\end{array}$ & Jumlah Karyawan & Kategori \\
\hline $\mathbf{0}-\mathbf{5 0}$ & $\mathbf{0}$ & Rendah \\
\hline $\mathbf{5 1}-\mathbf{7 0}$ & $\mathbf{0}$ & Sedang \\
\hline $\mathbf{7 1}-\mathbf{1 0 0}$ & $\mathbf{3}$ & Tinggi \\
\hline & \multicolumn{2}{c}{ Sumber : Hasil Penelitian }
\end{tabular}

2) Kategori Beban Kerja

Dari hasil perhitungan workload diatas sesuai bagian pekerjaan dapat diketahui jumlah operator yang mengalami beban kerja dengan kategori tinggi sebanyak 3 orang. Hasil tersebut bisa di katakan cukup mewakili beban kerja yang dialami para operator.

\section{Fishbone Diagram}

Diagram tulang ikan atau fishbone diagram adalah salah satu metode atau tool di dalam meningkatkan kualitas[10]. Fishbone Diagram digunakan ntuk mengetahui faktor-faktor yang mempengaruhi beban kerja yang dialami oleh para karyawan dapat menggunakan pendekatan diagram sebab akibat. Berikut ini akan dijelaskan mengenai hubungan sebab akibat adanya beban kerja menggunakan fishbone diagram. 


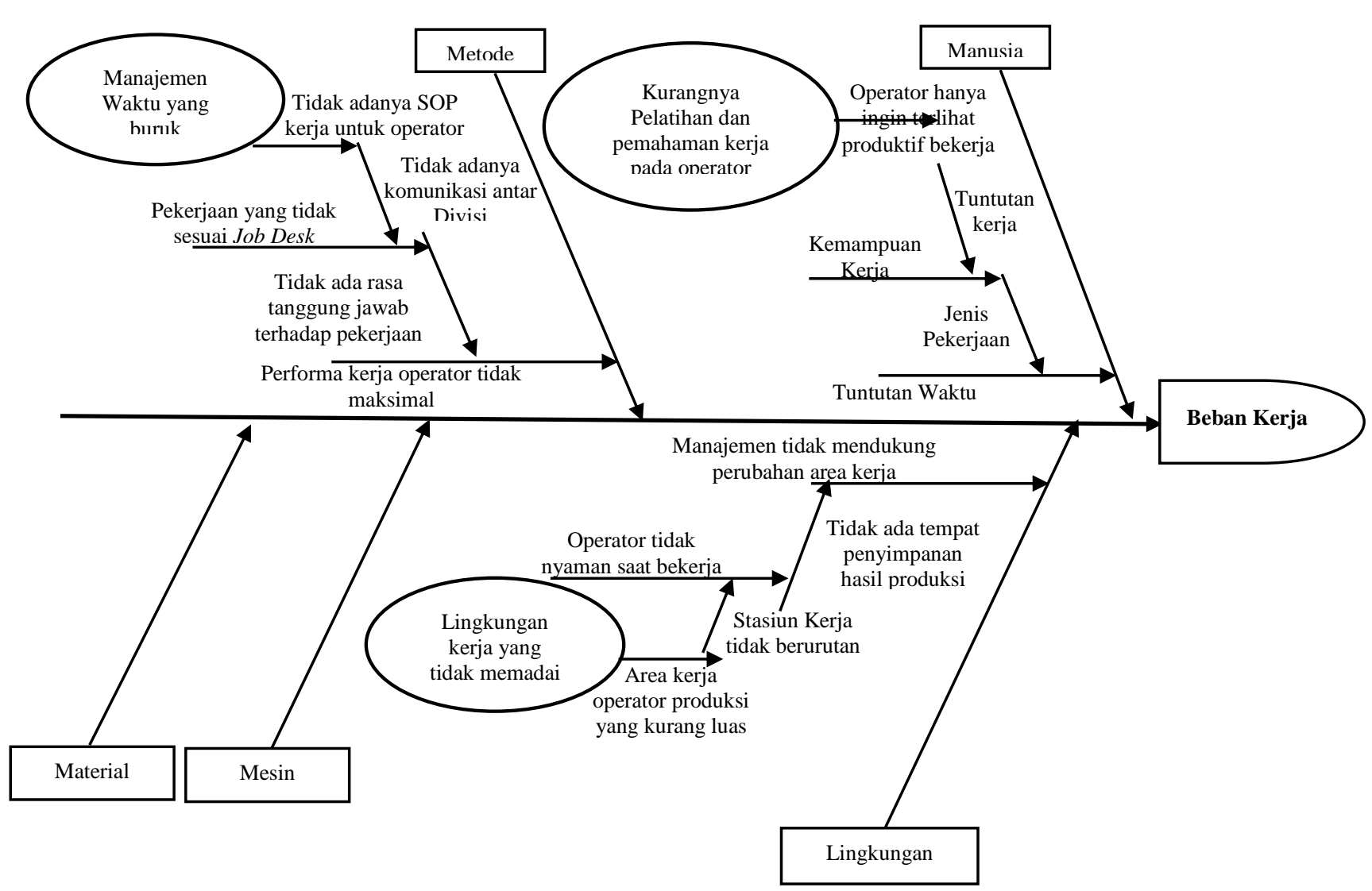

Gambar 1. Fishbone Diagram

Sumber : Hasil Penelitian

Dalam analisis Fishbone Diagram faktorfaktor yang menyebabkan terjadinya beban kerja pada operator produksi di karenakan manajemen waktu yang buruk dari perusahaan sehingga menimbulkan performa kerja operator yang tidak maksimal, kurangnya pelatihan dan pemahaman kerja pada operator sehingga menimbulkan rasa tuntutan kerja pada operator produksi dan lingkungan kerja yang tidak memadai sehingga menimbulkan rasa tidak nyaman saat operator bekerja.

\section{SIMPULAN}

Berdasarkan hasil penelitian dapat disimpulkan sebagai berikut:

1. Beban kerja mental yang paling besar di rasakan oleh operator produksi hammer mill pada saat proses pengukuran dan pemotongan bahan dengan nilai rata-rata beban kerja operator sebesar 76,67 dengan indikator workload mental demand dan workload temporal demand dengan nilai sebesar 75,00. Dengan nilai ratarata beban kerja (nilai wight workload) sebesar 73,56 dan nilai indikator tersebut dapat di katakan beban kerja yang dirasakan oleh operator Tinggi (71-100).

2. Faktor penyebab beban kerja mental ada 3 (tiga) yaitu kurangnya pelatihan dan pemahaman kerja pada operator, manajemen waktu yang buruk dan lingkungan kerja yang tidak memadai. Yang paling dominan dirasa oleh operator hammer mill di lantai produksi adalah tuntutan kerja dari segi manusia. Karena pada CV. Bahagia Jaya Alsindo tuntutan kerja yang di berikan oleh 
perusahaan di sama ratakan antara operator lama dan operator baru.

3. Dalam penelitian ini, solusi yang diberikan untuk perusahaan adalah perbaikan pada sistem kerja seperti mengadakan psikotest untuk operator produksi hammer mill yang baru bekerja, memberikan pelatihan untuk operator produksi dan membagi jam kerja pada operator produksi hammer mill.

\section{DAFTAR PUSTAKA}

[1] Tarwaka and S. H. A. Bakri, Ergonomi untuk Keselamatan, Kesehatan Kerja dan Produktivitas.. Surakarta:Uniba Press, 2016.

[2] R. I. P. Sari, "Pengukuran Beban Kerja Karyawan Menggunakan Metode NASA-TLX Di PT. Tranka Kabel," Sosio-E-Kons, vol.9, no.3, pp. 223-231, 2017.

[3] M. A. Bora, "Analisis Tingkat Beban Kerja Operator Packing Dengan Metode NASA-TLX (Task Load Index Di PT Gembira," JTIBSI, vol. 1, no. 1, pp. 66-75, 2016.

[4] Chandra, R., \& Adriansyah, D., "Pengaruh Beban Kerja dan Stres Kerja terhadap Kinerja Karyawan pada PT. Mega Auto Central Finance Cabang di Langsa", Jurnal Manajemen Dan Keuangan, vol. 6, no.1, pp. 670-678, 2017.
Gawron, Valerie. Human Performance, Workload, and Situational Awareness Measures Handbook. Florida: CRC Press, 2008.

[6] Kemendagri. Peraturan Menteri Dalam Negeri Nomor 12 Tahun 2008. www.depdagri.go.id. Diakses pada 12 Mei 2020

[7] Waluyo, M. Psikologi Teknik Industri. Jakarta: Graha Ilmu, 2010.

[8] H. Amri, "Analisis Beban Kerja Psikologis dengan Menggunakan Metode NASA-TLX pada Operator Departemen Fiber Line di PT . Toba Pulp Lestari," Industrial Engineering Journal, vol. 6, no. 1, pp. 29-35, 2017.

[9] V. M. Afma, "Analisa Beban Kerja Operator Inspeksi Dengan Metode NASA-TLX (Task Load Index) Di PT. XYZ," Profisiensi, vol. 4, no. 2, pp. 118-122, 2016.

[10] H. Murnawan, "Perencanaan Produktivitas Kerja Dari Hasil Evaluasi Produktivitas Dengan Metode Fishbone Di Perusahaan Percetakan Kemasan Pt . X Latar Belakang Masalah," J. Tek. Ind. HEURISTIC, vol 11, no 1, pp. 2746, 2014. 